\title{
Banka Kredileri, Para Arzı ve Ekonomik Büyüme Arasındaki İlişki: Türkiye Örneği
}

\author{
DOI: 10.26466/opus.873635 \\ $*$ \\ Filiz Yetiz* - Ayşe Ergin Ünal ** \\ * Dr. Öğretim Üyesi- Akdeniz Üniversitesi,UBF, Finans ve Bankacılık Bölümü \\ E-Posta: filiz.yetiz@gmail.com \\ ORCID: 0000-0001-5480-9268 \\ ** Dr. Öğretim Üyesi, Tarsus Üniversitesi,UBF, Finans ve Bankacıllk Bölümü \\ E-Posta: ayseerginunal@tarsus.edu.tr \\ ORCID: 0000-0001-6551-8933
}

\section{Öz}

Bankalar ekonomide tasarruflarm toplanması, fon fazlasının ihtiyacı olan ekonomik birimlere aktarılması, para ve sermaye piyasasının geliştirilmesinde çeşitli finansal hizmetler sunan kurumlardır. Bankaların büyümeyi destekleyici etkin kredi kanalıyla para arzı genişlemekte, tasarrufların ise verimli yatırımlara dönüştürülmesi sağlanarak yeni istihdam olanakları yaratılmaktadır. Diğer bir değişle banka kredileri sürdürülebilir ekonomik büyüme için önemli bir unsurdur. Çalışmanın amacı, veri alınan dönemde Türkiye'nin ekonomik büyümesine yönelik finansal borçluluğu temsil eden banka kredileri ve uygulanan para politikalarının yönünü gösteren para arzı etkisinin tespit edilmesidir. Bu nedenle çalışmada banka kredileri, para arzı ve ekonomik büyüme arasındaki nedensellik ilişkisi araştırılmıştır. Çalışmada, banka kredileri, para arzı ile ekonomik büyüme ilişkisi 2005:01-2020:11 dönemi aylık veriler kullanılarak Türkiye ekonomisi için analiz edilmiştir. Çalışmada ARDL sınır testi yaklaşımı kullanılmış ve değişkenler arasındaki nedensellik ilişkisinin araştırılmasında Toda-Yamamoto Nedensellik testi yaklaşımı uygulanmıştır. Analizden elde edilen bulgulara göre, hem uzun hem de kısa dönemde bankacıllk sektörü kredilerindeki artışın Türkiye'de ekonomik büyümeyi desteklediği, para arzındaki artışın ise kısa dönemde ekonomik büyümeyi sağladığı sonucuna ulaşılmıştır.

Anahtar Kelimeler: Banka Kredileri, Para Arzı, Ekonomik Büyüme, ARDL Sınır Testi, TodaYamamoto Nedensellik Testi 


\title{
Relationship Between Bank Loans, Money Supply And Economic Growth: Turkey Example
}

\begin{abstract}
Banks are institutions that provide various financial services in the collection of savings in the economy, the transfer of funds to the economic units they need, and the development of the money and capital market. Banks' money supply expands through effective loans to support growth, while savings are transformed into efficient investments, creating new employment opportunities. In other words, bank loans are an important element for sustainable economic growth. The aim of the study is to determine the effect of money supply indicating the direction of bank loans and monetary policies implemented, which represent financial indebtedness to Turkey's economic growth during the period of data retrieval. Therefore, the causality relationship between bank loans, money supply and economic growth was investigated in the study.In the study, bank loans, the relationship between money supply and economic growth were analyzed for the Turkish economy using monthly data for the period 2005:01-2020:11. $n$ the study, ARDL boundary testing approach was used and Toda-Yamamoto Causality test approach was applied in the investigation of causality relationship between variables. According to the findings obtained from the analysis, it was found that the increase in banking sector loans in both the long and short term supported economic growth in Turkey, while the increase in the money supply provided economic growth in the short term.
\end{abstract}

Keywords: Bank Loans, Money Supply, Economic Growth, ARDL Boundary Test, Toda-Yamamoto Causality Test 


\section{Giriş}

Para politikası faaliyetlerinin reel ekonomiye aktarılmasında oldukça önemli görevler alan banka kredi kanalı finansal sistem içerisinde bankaların işlevliğini artıran, dolayısıyla onların kullandırdığı kredilerden kaynaklı olarak ekonominin gelişmesine de katkı sağlayan bir mekanizmadır (Kashyap ve Stein,1993:3-5). Bankalar kredi fonları ile parasal aktarım mekanizmasının işleyişinde önemli bir yere sahiptir ve ekonominin büyümesi için gerekli fon kaynaklarının verimli bir şekilde kullanılmasını sağlamaktadırlar. Ayrıca ekonomik büyüme, finansal hizmetlere yönelik talebi arttırmakta ve finansal sistemin gelişmesini hızlandırmaktadır (Robinson, 1952). Para arzı ile büyüme arasındaki ilişki ise genişletici veya daraltıcı para politikalarıyla ilgilidir. Para arzını artırma amaçlı uygulanan para politikaları genişletici para politikası olarak, para arzını düşürmeye yönelik para politikaları ise daraltıcı para politikalarıdır (Arıcan ve Okay,2014, s.4). Genişletici bir para politikası, ekonomide faiz oranlarının düşmesine ve yurtiçi yatırımların hızlanarak ulusal gelirin artmasına neden olmaktadır.

Bu çalışmada, banka kredileri ve para arzının ekonomik büyüme üzerindeki etkisi araştırılmıştır. Çalışmanın amacl, veri alınan dönemde Türkiye'nin ekonomik büyümesine yönelik finansal borçluluğu temsil eden banka kredileri ve uygulanan para politikalarının yönünü gösteren para arzı etkisinin tespit edilmesidir. Ayrıca Türkiye de banka kredilerdeki gelişmeye bağlı olarak mı ekonomik büyüme gerçekleşiyor, ekonomik büyümenin sonucunda mı banka kredi hacmi ya da para arzı artıyor, ekonomik büyüme ile para arzı ve banka kredileri arasında çift yönlü bir nedensellik ilişkisi var mıdır sorularına yanıt aramaktır. Bu sorulara yönelik olarak elde edilen tespitler ışığında sunulan öneri ve tavsiyeler ile çalışmanın literatüre katkı sağlayacağ 1 düşünülmektedir. Çalışmada 2005:01-2020:11 dönemlerini kapsayan aylık veriler kullanılmıştır. Banka kredileri, para arzı ve ekonomik büyüme arasındaki ilişkinin incelenmesi kapsamında bağımlı değişken olarak büyüme oranını temsilen sanayi üretim endeksi, bağımsız değişken olarak ise para arzı ve toplam kredi miktarlarını temsilen banka kredileri değişkenleri seçilmiştir.

Değişkenler arasındaki eşbütünleşme ilişkisi tespiti için ARDL sınır testi yaklaşımı ve nedensellik ilişkilerini incelemek için ise Toda-Yamamoto Nedensellik testi yaklaşımı uygulanmıştır. Çalışmada kredilerin ekonomik bü- 
yüme açısından önemi, parasal aktarım mekanizması çerçevesinde para arzının krediler ve ekonomik büyüme üzerine etkisi teorik açıdan değerlendirilmiştir. Banka kredileri, para arzı ve ekonomik büyüme arasındaki ilişkiyi araştıran çalışmalarla ilgili yaklaşımlar literatür kısmında özetlenmiştir. İzleyen bölümlerde veri seti ve yöntem hakkında bilgilere yer verilmiştir. Sonuç bölümünde ise elde edilen bulgular tartışlarak genel bir değerlendirme yapilmıştır.

\section{Parasal Aktarım Mekanizması: Banka Kredileri Kanalı}

Parasal aktarım mekanizmaları para politikasındaki değişikliklerin ekonomik etkilerini reel üretime aktaran kanallardır. Literatürde en sık karşılaşılan parasal aktarım mekanizmaları; varlık fiyatları kanalı, faiz oranı kanalı, döviz kuru kanalı ve kredi kanalıdır. Kredi kanalı mekanizması çerçevesinde para politikasının ekonomi üzerine etkisi banka kredileri kanalı ile ortaya çıtığ 1 bilinmektedir. Kredi mekanizması literatüründe para politikası uygulamaları, banka kredi hacmini bankanın kullandırabileceği fon miktarını değiştirerek etkiler. Ayrıca para politikası bankaların kullandırabilecekleri fonların maliyetlerini de etkilemektedir. Bu bağlamda, fon maliyetleri değiştiğinde bankaların kredi verme yönündeki istekliliği de değişecektir (Öztürkler ve Çermikli,2007, s.58-59).

Parasal aktarım mekanizmalarının temelinde kredi ve para olmak üzere iki temel görüş bulunmaktadır. Aktarım mekanizmaları bu iki temel görüşün, para ve paraya çevrilebilecek kredinin üzerinden aktarımın yapılması üzerine şekillenmiştir. Para politikaları, ekonomik gelişmeyi destekleyici ve ekonomik büyümeye yönelik olarak kullanılmaktadır. (Türkmen,2020, s.19,104). Bankacilık sisteminde fon arz edenler ile fona talep edenler arasındaki ilişkiler krediler aracılığıyla kurulmaktadır. Para arzının belirlenmesi için uygulanan politikalar ise parasal aktarım mekanizması yoluyla kredi kanalını etkilemekte ve bu etkiler reel ekonomiye yansımaktadır. 


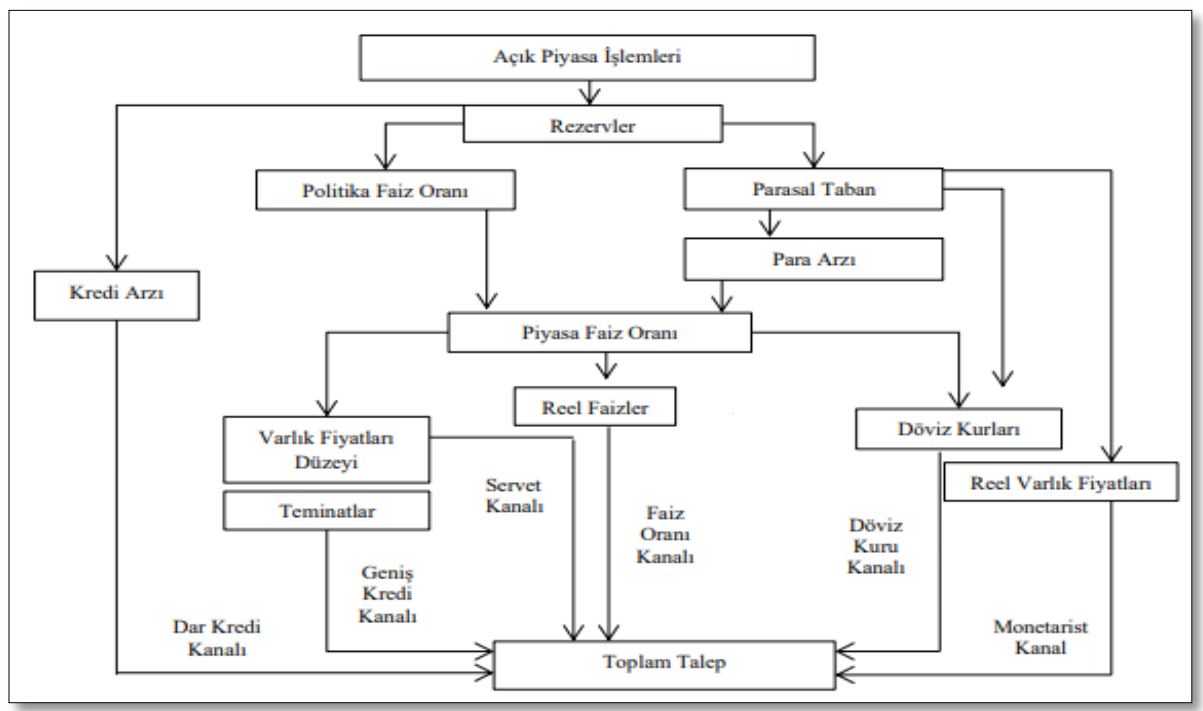

Şekil 1. Parasal Aktarım Mekanizmasının İşleyişi (Kuttner ve Mosser, 2002, s.16)

Kuttner ve Mosser (2002)'e göre Şekil 1'de parasal aktarım mekanizmasinın farklı kanallardan işleyişi özetlenmiştir. Parasal aktarım mekanizmasında dar ve geniş anlamlı bankaların borç verme kredi sistemleri gösterilmiştir. Banka kredileri kanalının işleyişinde para politikası uygulaması banka rezervlerini değiştirerek bankaların kredi verme olanaklarını etkilemektedir. Kredi kanalı para politikalarıyla bankaların kredi verme imkanlarını hem genişletip hem daraltarak ekonomide harcama ve yatırım kararları ile hasılayı, büyümeyi etkilemektedir (Holtemöller, 2002, s.4).

\section{Banka Kredileri, Para Arzı ve Ekonomik Büyüme İlişkisi}

Bankacılık sektörünün sağladığı krediler, ekonomik büyümenin devamlılığının sağlanması için önemli bir finansal kaynaktır. Ekonomideki kurumlar veya şirketler gelişmek ve büyümek için bankalardan aldıkları krediler ile fon ihtiyaçlarını karşılamaya çalışmaktadırlar (Şahin, 2011, s.9).

Banka kredilerindeki azalma ekonomik büyümeyi olumsuz yönde etkileyebilmektedir. Gelişmekte olan ülkelerde özellikle kriz dönemlerinde bankacllık sektörü likit kalmayı tercih etmekte ve bu dönemlerde geri dönmeyen 
kredilerin miktarı artmaktadır. Bu bağlamda bankalar kredilendirme aşamasinda titiz ve seçici davranmakta, mevduatların ortalama vadeleri düşmekte bu durum da uzun vadeli kredilendirme sürecini zorlaştırmaktadır. Sonuç olarak büyüme yavaşlamakta ve de bankalarca verilen toplam kredi miktarı azalmaktadır (İşcan, 2003, s.14).

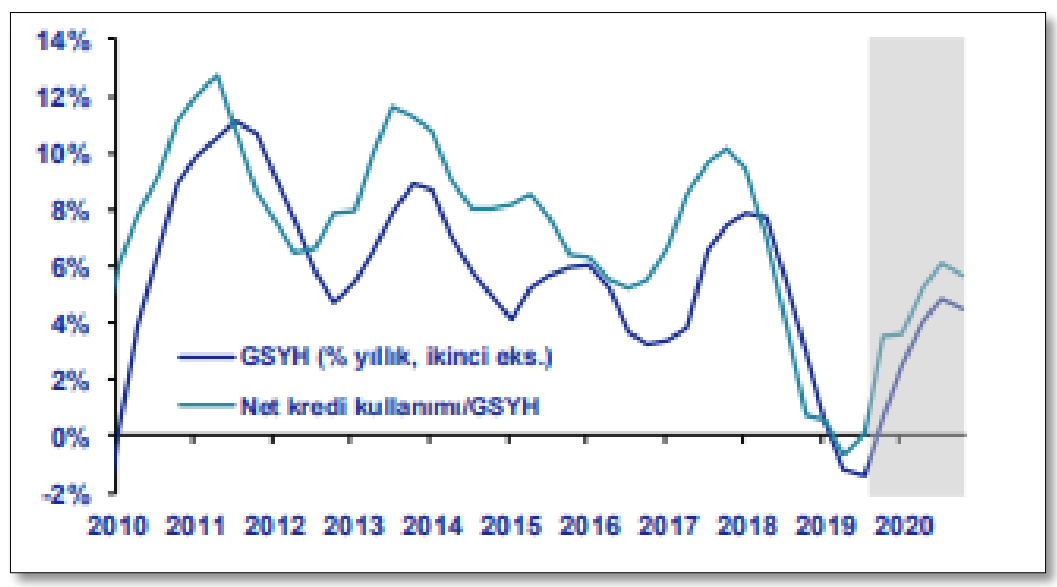

Şekil 2: Kredi kullanımı ve GSYH büyümesi(TüIK, BDDK, QNB Finansbank)

Şekil 2'de Türkiye ekonomisindeki net kredi ve büyümenin gelişimi gösterilmiştir. Türkiye ekonomisi için finansal sistemin gelişimiyle birlikte 2010 yılından günümüze banka kredilerinin artışı ve GSYH büyümesi arasında güçlü bir ilişki olduğu görülmektedir. Ekonomide genişletici bir para politikası para arzını artırıcı faiz oranını düşürücü bir etki yapmaktadır. Faiz oranlarına bağlı olarak iç yatırımlar artacak bu da milli geliri yükseltecektir. Milli gelirin yükselmesi ise yabanc mal ve hizmetlere olan talebi artırmaktadır.Böylece, döviz talebi artar ve serbest değişken döviz kur sisteminde döviz kurunu yükselterek ulusal paranın değer kaybetmesine neden olmaktadır. Ulusal paranın değer kaybetmesi net ihracatı artırarak ulusal geliri artırır (Oktar ve Dalyancı,2012, s.3). 

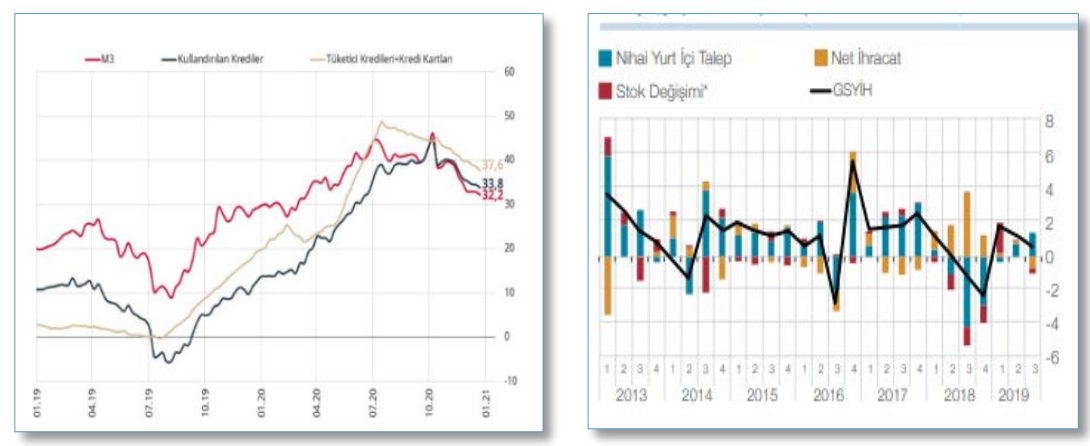

Şekil 3: M3 Para Arzı, Verilen Krediler GSYïH'in Gelişimi (Yıllık\% Büyüme) (TCMB, 2019, s.1; 2021, s.21).

TCMB, finansal istikrar raporuna göre; ilk çeyrekteki kredi büyümesinin devam ettiği ve yıllık büyümenin pozitif yönde etkilendiği görülmektedir. Bu dönemde finansal oynaklık ve belirsizliklerdeki azalışla birlikte kredi kullanımındaki artışa bağlı olarak ta yurt içi talep desteklenmiştir. Bu durum bankaların vermiş oldukları kredi miktarların artığını göstermektedir. M3 geniş para arzının ise kredilerdeki artışla paralel bir seyir izlediği ve büyüdüğü söylenebilir.

\section{Literatür İncelemesi}

$\mathrm{Bu}$ alandaki literatür incelendiğinde, banka kredileri ve ekonomik büyüme arasındaki ilişkiyi araştıran çalışmalar daha çok finansal gelişme ile ekonomik büyüme şeklindedir. Finansal gelişme ile ekonomik büyüme arasındaki ilişkiyi araştıran çalışmaların bir kısmı aşağıda özetlenmiştir. Ampirik çalışmalarda elde edilen bulgular kullanılan değişkenler, uygulanan metotlar ile ülkeler özelinde farklılık göstermektedir. Literatürde yapılan çalışmalarda, finansal gelişme ve ekonomik büyüme arasındaki nedensellik ilişkisinin tek yönlü olduğu, iki değişken arasında çift yönlü bir nedensellik ilişkisinin olduğu, bazı çalışmalarda ise iki değişken arasında nedensellik ilişkisinin olmadığı tespit edilmiştir. Para arzı ile ekonomik büyüme arasında ne tür bir ilişkinin olduğunu açıklayan ampirik çalışmalarda bu kısımda yer verilmiştir. Finansal gelişmenin ekonomik büyümeyi pozitif yönde etkilediği yönündeki çalışmalara, King ve Levine (1993), Rajan ve Zingales (1998), Levine ve 
Zervos (1998), Calderon ve Liu (2002), Jalilian ve Kirkpatrick (2002), ile Beck ve Levine (2004) örnek gösterilebilir. Banka kredileri, finansal gelişme ve ekonomik büyüme arasındaki ilişkiyi araştıran literatür çalışmaları Tablo 1'de özetlenmiştir.

Tablo 1. Kredi Hacmi, Para Arzı ve Ekonomik Büyüme İlişkisi Literatür

\begin{tabular}{|c|c|c|c|c|}
\hline Yazar/Yazarlar & $\begin{array}{l}\text { Seçilen } \\
\text { Ülke/Ülkeler }\end{array}$ & Ekonometrik Yöntem & Değişkenler & Sonuç \\
\hline $\begin{array}{l}\text { King ve Levine } \\
\text { (1993) }\end{array}$ & $\begin{array}{l}\text { Seçilmiş } \\
80 \text { ülke- } \\
1960-1989\end{array}$ & Panel regresyon modeli & $\begin{array}{l}\text { Banka kredileri, Para } \\
\text { arzı ve GSYİH }\end{array}$ & $\begin{array}{l}\text { Finansal gelişme, } \\
\text { ekonomik büyüme } \\
\text { ve para arzı arasında } \\
\text { güçlü bir ilişkinin } \\
\text { var olduğu sonu- } \\
\text { cuna ulaşmışlardır. }\end{array}$ \\
\hline $\begin{array}{l}\text { Kar ve Pente- } \\
\text { cost }(2000)\end{array}$ & $\begin{array}{l}\text { Türkiye-1963- } \\
1995\end{array}$ & $\begin{array}{l}\text { Eş-bütünleşim ve vektör } \\
\text { hata düzeltme modelin }\end{array}$ & $\begin{array}{l}\text { Para arzı, Mevduat- } \\
\text { lar, Özel Sektöre Aç- } \\
\text { lan Krediler ve Top- } \\
\text { lam Kredilerin Gelire } \\
\text { Oranı ile Ekonomik } \\
\text { Büyüme }\end{array}$ & $\begin{array}{l}\text { Para arzı dışındaki } \\
\text { diğer değişkenler } \\
\text { için ekonomik büyü- } \\
\text { meden finansal ge- } \\
\text { lişmeye tek yönlü bir } \\
\text { nedenselliğin varlı- } \\
\text { ğını göstermektedir. }\end{array}$ \\
\hline $\begin{array}{l}\text { Shan ve Morris } \\
(2002)\end{array}$ & $\begin{array}{l}\text { Çin ve } 19 \text { Eko- } \\
\text { nomik İşbirliği } \\
\text { ve Kalkınma } \\
\text { Örgütü Ülke- } \\
\text { leri/1985-1998 }\end{array}$ & $\begin{array}{l}\text { VAR Modeli,Granger } \\
\text { Nedensellik Testi ve } \\
\text { Toda-Yamamoto Neden- } \\
\text { sellik Testi }\end{array}$ & $\begin{array}{l}\text { Toplam kredi- } \\
\text { ler/GSYIH, } \\
\text { Borçlanma ve faiz } \\
\text { oranları, ile Ekono- } \\
\text { mik Büyüme }\end{array}$ & $\begin{array}{l}\text { Bazı ülkelerde ne- } \\
\text { denselliğin yönünün } \\
\text { ekonomik büyüme- } \\
\text { den finansal geliş- } \\
\text { meye doğru olduğu } \\
\text { yönünde ve değiş- } \\
\text { kenler arasında çift } \\
\text { yönlü nedenselliğin } \\
\text { bulunduğu yö- } \\
\text { nünde sonuçlar tes- } \\
\text { pit edilmiştir. }\end{array}$ \\
\hline $\begin{array}{l}\text { Jalilian and } \\
\text { Kirkpatrick } \\
(2002)\end{array}$ & 42 ülke & Panel Regresyon & $\begin{array}{l}\text { Banka kredileri ve } \\
\text { GSYİH }\end{array}$ & 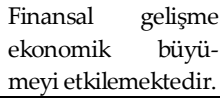 \\
\hline $\begin{array}{l}\text { Aslan ve Küçü- } \\
\text { kaksoy (2006) }\end{array}$ & $\begin{array}{l}\text { Türkiye 1970- } \\
2004\end{array}$ & $\begin{array}{l}\text { Granger Nedensellik } \\
\text { Testi }\end{array}$ & $\begin{array}{l}\text { Özel sektör finansal } \\
\text { aracıllk hizmetleri, } \\
\text { özel sektör kredi } \\
\text { hacmi büyüklüğü ve } \\
\text { Ekonomik Büyüme }\end{array}$ & $\begin{array}{l}\text { Finansal gelişmeden } \\
\text { ekonomik büyü- } \\
\text { meye doğru neden- } \\
\text { selliğin olduğu so- } \\
\text { nucu bulunmuştur. }\end{array}$ \\
\hline $\begin{array}{l}\text { Öztürkler ve } \\
\text { Çermikli (2007) }\end{array}$ & $\begin{array}{l}\text { Türkiye-1990- } \\
2006\end{array}$ & VAR Analizi & $\begin{array}{l}\text { Para politikası ölçüm } \\
\text { aracı olarak seçilen } \\
\text { faiz oranları ve } \\
\text { Banka Kredileri }\end{array}$ & $\begin{array}{l}\text { Para politikası şokla- } \\
\text { rından bankaları } \\
\text { verdikleri kredilere } \\
\text { doğru tek yönlü bir } \\
\text { ilişki, kredi ile sanayi } \\
\text { üretimi arasında iki } \\
\text { yönlü bir ilişki bu- } \\
\text { lunmuştur. }\end{array}$ \\
\hline
\end{tabular}




\begin{tabular}{|c|c|c|c|c|}
\hline Öztürk (2008) & $\begin{array}{l}\text { Türkiye -1975- } \\
2005\end{array}$ & $\begin{array}{l}\text { Eşbütünleşme Testi, VAR } \\
\text { Analizi ve Granger Ne- } \\
\text { densellik }\end{array}$ & $\begin{array}{l}\text { Özel sektör kredileri/ } \\
\text { GSYIHH ve Ekonomik } \\
\text { Büyüme }\end{array}$ & $\begin{array}{l}\text { Finansal gelişme ve } \\
\text { ekonomik büyüme } \\
\text { arasında uzun vadeli } \\
\text { bir ilişki olmadığını } \\
\text { tespit etmiştir. }\end{array}$ \\
\hline $\begin{array}{l}\text { Ceylan ve Dur- } \\
\text { kaya (2010) }\end{array}$ & $\begin{array}{l}\text { Türkiye 1998- } \\
2008\end{array}$ & $\begin{array}{l}\text { Hata düzeltme modeli, } \\
\text { Granger Nedensellik mo- } \\
\text { deli }\end{array}$ & $\begin{array}{l}\text { Banka kredi hacmi } \\
\text { ve Ekonomik Bü- } \\
\text { yüme }\end{array}$ & $\begin{array}{l}\text { Banka kredilerinden } \\
\text { büyümeye doğru } \\
\text { nedensellik ilişkisi } \\
\text { tek yönlüdür. }\end{array}$ \\
\hline Ndako (2010) & $\begin{array}{l}\text { Nijerya-1961- } \\
2007 \text { ve Güney } \\
\text { Afrika/1983- } \\
2007\end{array}$ & $\begin{array}{l}\text { VAR ve VECM Mo- } \\
\text { deli,Genelleştirilmiş } \\
\text { Darbe Tepki Fonksiyon- } \\
\text { ları ve Varyans Ayrıştır- } \\
\text { ması }\end{array}$ & $\begin{array}{l}\text { Özel sektör banka } \\
\text { kredisi, likit yüküm- } \\
\text { lülükler ve özel sek- } \\
\text { tör yurtiçi kredisi, pi- } \\
\text { yasa kapitalizas- } \\
\text { yonu, ciro oranıve iş- } \\
\text { lem gören hisse se- } \\
\text { netleri ve Ekonomik } \\
\text { Büyüme }\end{array}$ & $\begin{array}{l}\text { Ülke özelinde eko- } \\
\text { nomik büyümeden } \\
\text { finansal gelişmeye } \\
\text { doğru, finansal ge- } \\
\text { lişme ile ekonomik } \\
\text { büyüme arasında } \\
\text { çft yönlü nedensel- } \\
\text { lik ilişkisi sonuçları } \\
\text { bulunmuştur }\end{array}$ \\
\hline $\begin{array}{l}\text { Demirhan vd. } \\
\text { (2011) }\end{array}$ & $\begin{array}{l}\text { Türkiye/ 1987- } \\
2006\end{array}$ & $\begin{array}{l}\text { Vector Error Correction } \\
\text { Modeli }\end{array}$ & $\begin{array}{l}\text { Banka kredileri ve } \\
\text { GSYİH }\end{array}$ & $\begin{array}{l}\text { Banka kredileri ve } \\
\text { ekonomik büyüme } \\
\text { arasında çift yönlü } \\
\text { ilişki tespit edilmiş- } \\
\text { tir. }\end{array}$ \\
\hline $\begin{array}{l}\text { Vurur ve Özen } \\
\text { (2013) }\end{array}$ & $\begin{array}{l}\text { Türkiye/1998- } \\
2012\end{array}$ & Granger Nedensellik testi & $\begin{array}{l}\text { Banka kredileri, } \\
\text { Mevduat ve GSYİH }\end{array}$ & $\begin{array}{l}\text { Ekonomik büyüme- } \\
\text { den krediye doğru, } \\
\text { mevduatlardan eko- } \\
\text { nomik büyümeye ve } \\
\text { mevduatlardan kre- } \\
\text { diye doğru tek yönlü } \\
\text { nedensellik ilişkisi } \\
\text { tespit edilmiştir. }\end{array}$ \\
\hline $\begin{array}{l}\text { Turgut ve Ertay } \\
\text { (2016) }\end{array}$ & $\begin{array}{l}\text { Türkiye/2003- } \\
2013\end{array}$ & $\begin{array}{l}\text { Granger nedensellik ve } \\
\text { Eşbütünleşme modeli }\end{array}$ & $\begin{array}{l}\text { Banka kredileri ve } \\
\text { Ekonomik Büyüme }\end{array}$ & $\begin{array}{l}\text { Bankacilık sektörün- } \\
\text { den ekonomik büyü- } \\
\text { meye doğru neden- } \\
\text { sellik ilişkisi tespit } \\
\text { edilmiştir. }\end{array}$ \\
\hline $\begin{array}{l}\text { Çeştepe ve Yil- } \\
\text { dırım (2016) }\end{array}$ & $\begin{array}{l}\text { Türkiye/1986- } \\
2015\end{array}$ & $\begin{array}{l}\text { VEC modeli ve Granger } \\
\text { nedensellik analizi }\end{array}$ & $\begin{array}{l}\text { Banka kredileri, para } \\
\text { arzı ve reel GSYİH }\end{array}$ & $\begin{array}{l}\text { Finansal gelişme ile } \\
\text { büyüme arasındaki } \\
\text { nedensellik ilişkisi } \\
\text { çift yönlüdür. }\end{array}$ \\
\hline $\begin{array}{l}\text { İnançlı, Altıntaş } \\
\text { ve İnal (2016) }\end{array}$ & $\begin{array}{l}\text { D-8 ülke- } \\
\text { leri/1997-2014 }\end{array}$ & $\begin{array}{l}\text { Delta Testi ile Wester- } \\
\text { lund-Edgerton Eşbütün- } \\
\text { leşme Testi }\end{array}$ & $\begin{array}{l}\text { Özel sektöre verilen } \\
\text { krediler ve Ekono- } \\
\text { mik Büyüme }\end{array}$ & $\begin{array}{l}\text { Finansal gelişmenin } \\
\text { ekonomik büyüme } \\
\text { üzerinde olumlu bir } \\
\text { etki oluşturduğu so- } \\
\text { nucuna ulaşlmiştır. }\end{array}$ \\
\hline $\begin{array}{l}\text { Karamelikli ve } \\
\text { Keskingöz } \\
(2017)\end{array}$ & $\begin{array}{l}\text { Türkiye/1998- } \\
2014 \text { dönemi } \\
\text { üçer aylık veri- } \\
\text { ler }\end{array}$ & $\begin{array}{l}\text { Granger Nedensellik } \\
\text { Analizi, } \\
\text { Toda Yamamato Yön- } \\
\text { temi }\end{array}$ & $\begin{array}{l}\text { Banka Kredileri, } \\
\text { Borsa İstanbul'un pi- } \\
\text { yasa değeri, Para arzı } \\
\text { (M2) ve GSYİH }\end{array}$ & $\begin{array}{l}\text { Krediler ile ekono- } \\
\text { mik büyüme arasın- } \\
\text { daki nedensellik iliş- } \\
\text { kisi çift yönlüdür. }\end{array}$ \\
\hline $\begin{array}{l}\text { Kamacı, Cey- } \\
\text { han ve Peçe } \\
(2017)\end{array}$ & $\begin{array}{l}\text { Türkiye- 2005- } \\
2017\end{array}$ & $\begin{array}{l}\text { Nedensellik ve DOLS ve } \\
\text { FMOLS testleri, Eşbütün- } \\
\text { leşme }\end{array}$ & $\begin{array}{l}\text { Para arzl, Yurtiçi } \\
\text { Kredi Hacmi ve Eko- } \\
\text { nomik Büyüme }\end{array}$ & $\begin{array}{l}\text { Para arzı değişkenin- } \\
\text { den yurtiçi kredile- } \\
\text { rine ve ekonomik }\end{array}$ \\
\hline
\end{tabular}




\begin{tabular}{|c|c|c|c|c|}
\hline & & & & $\begin{array}{l}\text { büyümeden ise yur- } \\
\text { tiçi kredilerine } \\
\text { doğru nedensellik } \\
\text { ilişkisinin tek yönlü } \\
\text { olduğu sonucu bu- } \\
\text { lunmuştur. }\end{array}$ \\
\hline $\begin{array}{l}\text { Sağlam ve Sön- } \\
\text { mez (2017) }\end{array}$ & $\begin{array}{lr}\text { Seçilmiş } & 9 \\
\text { Ülke/ } & \text { 2001- } \\
2014 & \end{array}$ & $\begin{array}{l}\text { Panel Veri Analizi, Delta } \\
\text { Testi ve Hurlin Panel Ne- } \\
\text { densellik Testi }\end{array}$ & $\begin{array}{l}\text { Banka likit rezerv- } \\
\text { leri/ GSYIHH, Banka } \\
\text { özel sektör yurtiçi } \\
\text { kredileri/ GSYİH, M2 } \\
\text { para arzı/GSYİH,faiz } \\
\text { yayılması/ GSYİH, } \\
\text { özel sektör yurtiçi } \\
\text { kredileri/ GSYİH ve } \\
\text { Ekonomik Büyüme }\end{array}$ & $\begin{array}{l}\text { Finansal gelişmeden } \\
\text { ekonomik büyü- } \\
\text { meye doğru tek } \\
\text { yönlü bir nedensel- } \\
\text { lik olduğu sonucuna } \\
\text { ulaşılmıştır. }\end{array}$ \\
\hline Akın (2019) & $\begin{array}{l}\text { Türkiye- 2006- } \\
2018\end{array}$ & $\begin{array}{l}\text { Granger Nedensellik } \\
\text { Testi }\end{array}$ & $\begin{array}{l}\text { M2 para arzı, piyasa } \\
\text { kapitalizasyonu/ } \\
\text { GSYIH,Ticari banka- } \\
\text { lar tarafından özel } \\
\text { sektöre verilen kredi- } \\
\text { ler/ GSYİH ve Eko- } \\
\text { nomik Büyüme }\end{array}$ & $\begin{array}{l}\text { Uzun dönemde eko- } \\
\text { nomik büyümeden } \\
\text { finansal gelişmeye, } \\
\text { kısa dönemde finan- } \\
\text { sal gelişmeden eko- } \\
\text { nomik büyümeye } \\
\text { doğru bir nedensel- } \\
\text { lik ilişkisi tespit edi- } \\
\text { miştir. }\end{array}$ \\
\hline Idris (2019) & $\begin{array}{l}\text { Nijerya-1980- } \\
2017\end{array}$ & $\begin{array}{l}\text { Eşbütünleşme, Granger } \\
\text { Nedensellik Testi }\end{array}$ & $\begin{array}{l}\text { Para arzl, Ekonomik } \\
\text { Büyüme }\end{array}$ & $\begin{array}{l}\text { Para arzından büyü- } \\
\text { meye doğru neden- } \\
\text { selliğin olduğu so- } \\
\text { nucuna ulaşlmıştır. }\end{array}$ \\
\hline Baykuş (2020) & $\begin{array}{l}\text { Türkiye/205- } \\
2019\end{array}$ & $\begin{array}{l}\text { Gecikmesi Dağıtılmış } \\
\text { Otoregresif } \\
\text { (ARDL) modeli }\end{array}$ & $\begin{array}{l}\text { M3 Para Arzı, Özel } \\
\text { Sektör } \\
\text { leri/GSYİH, Yredi- } \\
\text { Krediler/ GSYìiti, } \\
\text { Özel Sektör Kredi- } \\
\text { leri/ Yurtiçi Krediler } \\
\text { ve Ekonomik Bü- } \\
\text { yüme }\end{array}$ & $\begin{array}{l}\text { Finansal gelişme ve } \\
\text { ekonomik büyüme } \\
\text { arasında kısa ve } \\
\text { uzun dönemde pozi- } \\
\text { tif yönlü ilişkinin } \\
\text { varlığı tespit edilmiş- } \\
\text { tir. }\end{array}$ \\
\hline
\end{tabular}

Tablo 1'de, yapılan çalışmalarda Kar ve Pentecost (2000), Shan ve Morris (2002), Vurur ve Özen (2013), çalışmalarında ekonomik büyümeden finansal gelişmeye doğru bir nedensellik ilişkisi olduğunu, Aslan ve Küçükaksoy (2006), Ceylan ve Durkaya (2010),Turgut ve Ertay (2016), Sağlam ve Sönmez (2017) ise çalışmalarında finansal gelişmeden ekonomik büyümeye doğru bir nedensellik ilişkisi olduğu sonucuna ulaşmışlardır. Ayrıca Shan ve Morris (2002), Demirhan vd. (2011), Çeştepe ve Yıldırım (2016), Karamelikli ve Keskingöz (2017) çalışmalarında finansal gelişme ve ekonomik büyüme arasında çift yönlü bir nedensellik ilişkisinin olduğunu tespit etmişlerdir. Son olarak yapılan literatür taramasında uzun dönemde Öztürk (2008), finansal gelişme 
ve ekonomik büyüme arasında bir ilişki olmadığı sonucuna ulaşmıştır. Para arzı ve ekonomik büyüme arasındaki ilişkiyi inceleyen çalışmalardan Idris (2019) para arzından ekonomik büyümeye uzanan tek yönlü nedenselliğin varlığını tespit etmiştir. Kamacı vd, (2017), çalışmalarında para arzı, yurt kredi hacmi ile ekonomik büyüme arasında uzun dönemde bir eş bütünleme ilişkisinin olduğu sonucuna ulaşmışlardır.

\section{Ekonometrik Analiz}

Çalışmanın bu bölümünde banka kredileri, para arzı ve ekonomik büyüme arasındaki nedensellik ilişkisinin test edildiği ekonometrik analize yönelik gerekli olan veri seti özellikleri, model, yöntem ve bulgulara ilişkin bilgilere yer verilmektedir.

\section{Veri Seti ve Model}

Çalışmada model 2005:01-2020:11 dönemlerini kapsayan aylık veriler kullanılarak tahmin edilmiştir. Banka kredileri, para arzı ve ekonomik büyüme arasındaki ilişkinin incelenmesi kapsamında bağımlı değişken olarak büyüme oranını temsilen sanayi üretim endeksi (mpi), para arzını temsilen (lnm) ve banka kredilerini temsilen kamu özel banka ayrımı yapılmaksızın Türkiye' deki toplam kredi miktarlarına (lnc) ait ilgili dönem verileri kullanılmıştır. Diğer yandan tüm değişkenler Türkiye Cumhuriyet Merkez Bankası (TCMB)' ndan edinilmiş olup logaritmaları alınarak analize dahil edilmişlerdir. Analize ilişkin model ve grafikler aşağıdaki gibidir;

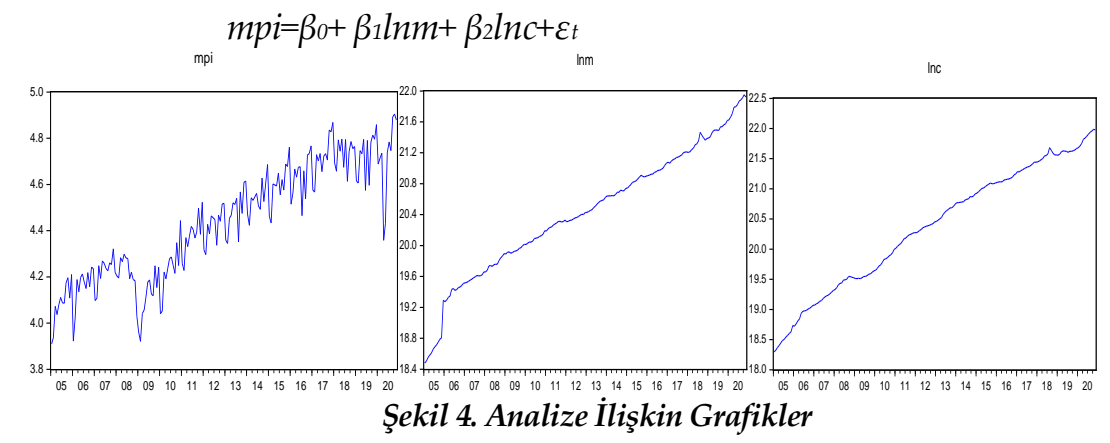




\section{Yöntem ve Bulgular}

Ekonometrik yöntemler kapsamında zaman serisine dayalı çalışmalarda yapılan ilk değerlendirme değişkenlerin birim kök durum tespitinin yapılması olup birim kök problemi yaşanan değişkenlerde sahte regresyon ile karşı karşıya kalınmaktadır. Bu nedenle çalışmada ilk olarak değişkenlerin durağanlık seviyelerinin belirlenmesine yönelik ADF (Augmented Dickey- Fuller) birim kök testi yapılmaktadır. Çalışmanın diğer kademesinde değişkenler arasındaki eşbütünleşme varlığının tespiti yapılmakta olup verilerin durağanlık durumlarına bağlı olarak uygulanabilen ARDL sınır testi yaklaşımı kullanılmış ve yine değişkenler arasındaki nedensellik ilişkisi Toda-Yamamoto Nedensellik testi kullanılarak sınanmıştır.

Ampirik analizlerde seriler arasındaki uzun dönemli ilişkinin tespiti doğrultusunda pek çok yöntem kullanılmaktadır. Engle-Granger (1987), Johansen (1988), Johansen-Juselius (1990) bunlardan birkaçı olup bu yöntemlerde değişkenlerin seviyede durağan olmaları ya da aynı seviyede durağan olmaları gerekmekte iken değişkenlere uygulanan fark alma işlemi veri kaybına neden olmaktadır (Koçak, 2014, s.68). Söz konusu testlere alternatif olup Peseran vd. (2001)' e ait çalışmada geliştirilen ARDL (Gecikmesi Dağıtılmış Otoregresif Modeller) modeline dayalı sınır testi yaklaşımıyla değişkenlerin durağanlık seviyeleri göz ardı ederek eşbütünleşme ilişkisi sınanabilmektedir (Peseran, 2001, s.290). Bu bağlamda çalışmada ARDL yaklaşımı kullanılmış olup modele ilişkin denklem şu şekildedir;

$$
\Delta Y_{t}=a_{0}+\sum_{i=1}^{m} a_{1 i} \Delta Y_{t-i}+\sum_{i=0}^{m} a_{2 i} \Delta X_{t-i}+a_{3} X_{t-1}+a_{4} X_{t-1}+\varepsilon_{t}
$$

Değişkenler arasındaki eşbütünleşme ilişkisinin sınandı̆̆ 1 ARDL Sınır Testi Yaklaşımı üç temel adımdan meydana gelmektedir. İlk adımda değişkenler arası uzun dönemli ilişkinin varlığı test edilmekte, eşbütünleşme ilişkisinin tespiti halinde ikinci ve üçüncü adım olan kısa/uzun dönem esneklikler sinanmaktadır (Yılancı, 2015, s.37). Analizde gecikme uzunluğunun belirlenmesinden ardından değişkenler arasındaki eşbütünleşme ilişkisi varlığ 1 test edilmektedir. Hesaplanan F istatistik değerinin, alt sınır I(0) ve üst sınır I(1) kritik değerlerinden yüksek olması durumunda eşbütünleşme ilişkisinin varlığ1 tespit edilmektedir. 
Eşbütünleşme durum tespitinin ardından yapılacak nedensellik analizinin değişkenler arasındaki ilişkiyi daha açıklayıcı hale getireceği düşünülmekte olup bu çalışmada nedensellik ilişkisi, serilerin durağanlık seviyelerini gözardı ederek analizin yapılmasına imkan veren Toda-Yamamoto nedensellik testi ile araştırılmıştır. Bu test kapsamında VAR modeli aracılı̆̆ ile gecikme uzunluğu ( $\mathrm{k}$ ) belirlenmekte ve bulunan gecikme uzunluğuna en yüksek bütünleşme derecesi (dmax) eklenerek analiz yapılmaktadır (Öztürk, 2020: 116). Diğer aşamada kullanılan çeşitli bilgi kriterleri veri alınarak uygun gecikme uzunluğu belirlenirken farklı birim kök testleri ile de maksimum bütünleşme tespit edilebilmektedir. Toda Yamamoto nedensellik testi metadolojik sıralamasında ilk olarak sistemde yer alan serilerin tümleşme derecesinin tespiti yapılmakta sonrasında ise sistem tahmin edilmektedir. Birim kök ve eşbütünleşme özelliklerinin tespitinde kullanılan potansiyel eğilimli ön testlere ihtiyaç olmaması yöntemi diğer nedensellik testlerine göre farklılaştırmakta olup (Kılıç ve Çütcü, 2018: 245) tahmin edilen eşitlikler aşağıdaki gibidir.

$$
\begin{aligned}
& Y_{t}=a_{0}+\sum_{\substack{i=1 \\
p+d \max }}^{p+d \max } a_{1(i+d)} Y_{t-(i+d)}+\sum_{\substack{i=1 \\
p+d \operatorname{dmax}}}^{p+d \max } a_{2(i+d)} X_{t-(i+d)}+\varepsilon_{t} \\
& X_{t}=\beta_{0}+\sum_{i=1}^{p+a} \beta_{1(i+d)} Y_{t-(i+d)}+\sum_{i=1}^{p+a} \beta_{2(i+d)} X_{t-(i+d)}+\varepsilon_{2 t}
\end{aligned}
$$

Yukarıdaki modellerden ilki öncül hipotez X değişkeninin, Y değişkeninin Granger nedeni olmadığını temsil ederken alternatif hipotez ise $X^{\prime}$ in $Y^{\prime}$ 'nin Granger nedeni olduğunu ifade etmektedir. $p$ serbestlik dereceli $X^{2}$ dağılıma uygunluk gösteren Wald testiyle test edilmektedir (Yılancı ve Özcan, 2010, s.28).

\section{Bulgular}

Değişkenlerin durağanlığını sınamak üzere uygulanan ADF birim kök testlerine ait hipotezler aşağıdaki şekildedir;

$\mathrm{H}_{0}$ : Birim kök vardır, seri durağan değildir.

$\mathrm{H}_{1}$ : Birim kök yoktur, seri durağandır. 
Tablo 2. ADF Birim Kök Testi Sonuçları

\begin{tabular}{|c|c|c|}
\hline \multirow{3}{*}{$\begin{array}{l}\text { Değişkenler } \\
\text { mpi }\end{array}$} & \multicolumn{2}{|l|}{ Sabitli ve Trendli } \\
\hline & Düzey & Birinci Fark \\
\hline & $-2.579725 \quad(0.2902)$ & $-4.883757(0.0005)^{*}$ \\
\hline $\operatorname{lnm}$ & $-4.179354(0.0058)^{*}$ & - \\
\hline $\ln c$ & $-2.944548 \quad(0.1511)$ & -11.27007 \\
\hline
\end{tabular}

NOT: ${ }^{*}{ }^{* *},{ }^{* * *}$ değerleri sırasıyla $\% 1, \% 5 \% 10$ anlam seviyelerinde serilerin durağanlıklarını göstermektedir.

Tablo 2'de yer alan ADF birim kök testi sonuçları, mpi ve lnc değişkenlerinin birinci farklarında I(1) durağan lnm değişkeninin ise düzeyde durağan I(0) olduğunu göstermektedir. Değişkenlerin birim kök testi sınaması öncesi trend içerip içermedikleri kontrol edilmiş ve söz konusu değerlerin her üç değişkende de 2.38 'den büyük olduğu belirlenerek sabit ve trendli değerleri raporlanmıştır. Bir sonraki aşama olan gecikme uzunluğunun belirlenmesine ilişkin bilgiler Tablo 2’ de yer almaktadır.

Tablo 3. Gecikme Uzunluklarmmn Tespiti

\begin{tabular}{lllllll}
\hline Lag & LogL & LR & FPE & AIC & SC & HQ \\
\hline 0 & 75.87287 & NA & $9.05 e-05$ & -0.796425 & -0.743810 & -0.775098 \\
\hline 1 & 1038.926 & 1884.006 & $2.68 e-09$ & -11.22324 & $-11.01278^{*}$ & -11.13793 \\
\hline 2 & 1057.332 & $35.40389^{*}$ & $2.42 e-09^{*}$ & $-11.32603^{*}$ & -10.95773 & $-11.17674^{*}$ \\
\hline 3 & 1058.845 & 2.859628 & $2.63 e-09$ & -11.24420 & -10.71806 & -11.03093 \\
\hline 5 & 1065.909 & 13.12595 & $2.68 e-09$ & -11.22305 & -10.53906 & -10.94580 \\
\hline 6 & 1074.706 & 16.05573 & $2.69 e-09$ & -11.22084 & -10.37900 & -10.87960 \\
\hline 7 & 1082.507 & 13.98176 & $2.73 e-09$ & -11.20773 & -10.20805 & -10.80251 \\
\hline 8 & 1088.342 & 10.26748 & $2.83 e-09$ & -11.17314 & -10.01562 & -10.70394 \\
\hline
\end{tabular}

Çalışmada uygun gecikme sayısı Tablo 3' den hareketle "2" olarak belirlendikten sonra ARDL sınır testi yaklaşımıyla değişkenler arasındaki eşbütünleşme ilişkisi sınanmaktadır.

Tablo 4. ARDL Sınır Testinin Sonuçları

\begin{tabular}{llll}
\hline $\boldsymbol{k}$ & F İstatistiği & Alt Sinir $(\% \mathbf{1 0}, \mathbf{\% 5}, \mathbf{\% 1})$ & Üst Sinir (\%5) \\
\hline & & 4.19 & \\
2 & \multirow{2}{*}{13.08364} & 4.87 & \\
& & 5.79 & \\
& 6.34 &
\end{tabular}

Not: k, bağımsız değişken sayısını göstermektedir. 
Tablo 4' deki ARDL sınır testi sonuçlarında sırasıyla \%5 \%10, \%5 ve \%1 anlamlılık seviyelerinde F istatistik değerinin (13.08) üst sınır değerlerinden büyük olduğu görülmekte olup bu sonuçlar değişkenler arasında eşbütünleşme ilişkisinin varlığını göstermektedir. Çalışmanın bir sonraki aşaması ARDL $(2,4,2)$ modeli kapsamında kısa ve uzun dönem ilişkileri tahmininden oluşmaktadır.

Tablo 5. Kısa Dönemin Analiz Sonuçları

\begin{tabular}{llll}
\hline Değişken & Katsayılar & t istatistik değerleri & Olasılık Değerleri \\
\hline$D($ mpi(-1)) & -0.149202 & -2.017500 & 0.0452 \\
\hline$D(\operatorname{lnm})$ & 0.023752 & 0.111350 & 0.9115 \\
\hline$D(\operatorname{lnm}(-1))$ & -0.605193 & -2.214195 & 0.0281 \\
\hline$D(\operatorname{lnm}(-2))$ & -0.425207 & -1.901049 & 0.0589 \\
\hline$D(\operatorname{lnm}(-3))$ & 0.354929 & 2.189070 & 0.0299 \\
\hline$D(\operatorname{lnc})$ & 0.172119 & 0.379645 & 0.7047 \\
\hline$D(\operatorname{lnc}(-1))$ & 0.862925 & 1.902832 & 0.0587 \\
\hline$D(@ T R E N D 0)$ & 0.001462 & 1.218098 & 0.2248 \\
\hline$C$ ointEq(-1) & -0.512957 & -6.243914 & 0.0000 \\
\hline
\end{tabular}

Not: ${ }^{*}$ ve ${ }^{* *}$ değerleri sirasıyla \%1 ve \%5 anlam seviyelerinde serilerin anlamlı olduğunu göstermektedir.

Hata düzeltme modelindeki katsayının negatif ve anlamlı olması durumunda analiz edilebilecek olan kısa dönem ilişkisi beklenen düzeydeki gibi olduğundan yorumlanabilmektedir. Hata düzeltme katsayısına (-0.51) göre kısa dönemdeki meydana gelen sapmanı \%51' i bir sonraki dönemde düzeltilmektedir. Buna göre, bir dönem önceki büyüme oranındaki azalış bugünkü büyüme oranını 0.14 birim azaltmakta iken kısa dönemde para arzı ve büyüme arasında ilk iki dönemde artan para arzı büyümeyi azaltırken üçüncü dönemde para arzındaki \%1'lik artışın büyümeyi \% 35 arttırdığı tespit edilmiştir. Diğer yandan banka kredilerindeki \%1' lik artışın büyümeyi \% 0.86 oranında arttırdığı bulgular arasındadır. Tablo 5 'teki kısa dönem sonuçlarından sonra uzun dönem analiz sonuçları Tablo 6' da yer almaktadır.

Tablo 6. Uzun Dönem Analiz Sonuçlarn

\begin{tabular}{llll}
\hline Değişken & Katsayılar & t istatistik dĕ̆erleri & Olasılik Değerleri \\
\hline $\boldsymbol{l n} m$ & -0.303954 & -2.712947 & 0.0073 \\
\hline $\boldsymbol{l n} \boldsymbol{c}$ & 0.312557 & 2.367305 & 0.0190 \\
\hline $\boldsymbol{c}$ & 3.990297 & 1.524411 & 0.1292 \\
\hline trend & 0.002850 & 1.221750 & 0.2234 \\
\hline
\end{tabular}


Çalışmanın bu kısmında uzun dönemli analiz sonuçları incelenmekte olup her iki değişkende anlamlıdır. Bu bağlamda uzun dönemde para arzındaki \%1'lik değişim büyümeyi \%30 oranında azaltırken banka kredilerindeki \%1'lik değişim büyümeyi \%31 artırmaktadır. Kısa dönem ve uzun dönem eşbütünleşme analizleri sonrası yapılan Toda-Yamamoto Granger Nedensellik test sonuçları aşağıda yer almaktadır.

Tablo 7. Toda Yamamoto Nedensellik Test Sonuçlan

\begin{tabular}{llll}
\hline Değişkenler & Sonuçlar & \\
\hline mpi (Bă̆ıml Değişken) & Ki-Kare P-değeri & \multicolumn{2}{c}{ İlişki ve Yönü } \\
\hline $\operatorname{lnm}$ & 0.0001 & $\operatorname{lnm}$ & mpi \\
\hline $\operatorname{lnc}$ & 0.0290 & $\operatorname{lnc}$ & mppi \\
\hline
\end{tabular}

Toda-Yamamoto Granger nedensellik testi sonuçları, para arzı ve banka kredi değişkenlerinin, ekonomik büyümenin Granger nedeni olup değişkenler arasında tek yönlü bir nedensellik ilişkisi olduğu görülmektedir.

\section{Sonuç}

Türkiye ekonomisinde banka kredileri ve para arzının ekonomik büyüme üzerindeki etkileri büyümenin istikrarlılığı, artışı ve yavaşlaması şeklinde olabilmektedir. Bankacılık sektörü kredi hacmindeki artış, para arzını etkileyerek üretimi ve istihdamı arttırmaktadır. Parasal aktarım mekanizması kanalıyla da banka kredileri ve para politikalarına göre değişen para arzı ekonomik büyümenin devamlılığını doğrudan ya da dolaylı olarak etkilemektedir. Banka kredileri, para arzı ile ekonomik büyüme arasındaki nedensellik ilişkisinin yönü üzerine literatürde seçilen ülke ve dönemler özelinde çok farklı sonuçların olduğu görülmektedir. Bu konudaki çalışmalardan bir kısmı banka kredilerindeki genişlemenin ekonomik büyümeye yol açtığını desteklerken, bir kısmı ekonomik büyümenin banka kredi artışını desteklediği, diğer bir kısım çalışmalarda ise ekonomik büyüme ve banka kredileri gelişiminin karşılıklı olarak birbirini etkilediğini ileri sürmektedir. Ayrıca para arzının ekonomik büyüme değişkenini ne yönde etkilediği de literatürde merak edilen bir konudur. Bu konu ve tartışmalar banka kredileri üzerinden ekonomik büyümeyi sağlamayı amaçlayan para politikalarının etkinliği açısından önemlidir. Çalışmanın amacı yukarıda belirtilen farklı ampirik sonuçları Türkiye ekonomisi için analiz etmektir. Bu kapsamda banka kredileri, para arzı 
ile ekonomik büyüme arasındaki ilişki 2005:01 ile 2020:11 dönemi içerisinde incelenmiştir. Analiz yöntemi olarak ARDL sınır testi yaklaşımı ve Toda-Yamamoto Nedensellik testi tercih edilmiştir.

ARDL sınır testi sonuçlarına göre, kısa dönemde para arzı ve büyüme arasında ilk iki dönem incelendiğinde artan para arzının büyümeyi azalttığı, üçüncü dönemde ise para arzındaki \%1'lik artışın büyümeyi \% 35 arttırdığı sonucuna ulaşılmıştır. Banka kredilerindeki \%1' lik artışın ise büyümeyi \% 0.86 oranında arttırdığı tespit edilmiştir. Uzun dönemde ise para arzındaki \%1'lik değişim büyümeyi \%30 oranında azaltırken banka kredilerindeki \%1'lik değişim büyümeyi \%31 artırmaktadır. Toda-Yamamoto Granger nedensellik testi sonuçları banka kredileri, para arzı ve büyüme değişkenleri arasında nedensellik ilişkisinin tek yönlü olduğunu göstermektedir.

Analiz sonuçları banka kredilerinin hem kısa hem de uzun dönemde büyümeyi desteklediğini göstermektedir. Bankacıllk sektörü kredi büyümesinin, literatürdeki bazı çalışmalar ile benzer şekilde yani Türkiye' deki büyüme üzerinde pozitif bir etkisi olduğu sonucu tespit edilmiştir. Bankacıllk sektörü kredilerinin ekonomik büyümeyi destekleyebilmesi için kredilerin işletme sermayesini ihtiyaçlarını finanse etmek dışında verimli yatırım alanlarına aktarılması oldukça önemlidir. Para arzı ise kısa dönemin ilk iki aşamasında büyümeyi azalttığı üçüncü dönemde ise ekonomik büyümeyi olumlu yönde etkilediği görülmektedir. Türkiye ekonomik büyümede para arz ziyade banka kredilerinin etkin olduğu görülmektedir. Elde edilen veriler, son dönemlerde Türkiye ekonomisinde büyümede banka kredilerinin daha etkin olduğu, para arzı artısıının ise ekonomik büyüme üzerinde baskın olmadığı sonucunu ortaya koymaktadır. Diğer bir değişle Türkiye' de uygulanan genişletici para politikaları kapsamında artan banka kredilerinin büyümeye ivme kazandırdığı görülmektedir. Bu bağlamda değerlendirilmesi gereken bir diğer nokta Ortodoks politikalar kapsamında farklı çeşit para politikası araçları yerine bankalara yönelik araçların kullanılması tercihidir. Keza çalışmada ekonomik büyümede banka kredileri ağırlığının oldukça yüksek olduğu görülmektedir. Son olarak sağlanan büyümenin sürdürülebilirliği önem arz etmekte olup söz konusu banka kredilerinin kullanım amacı doğru değerlendirilmelidir. Çalışmadan elde edilen sonuçların bundan sonraki yapılacak farklı çalışmalara katkı sağlayacağı düşünülmektedir. 


\title{
EXTENDED ABSTRACT
}

\section{Relationship Between Bank Loans, Money Supply And Economic Growth: Turkey Example}

\author{
Filiz Yetiz - Ayşe Ergin Ünal \\ Akdeniz University-Tarsus Üniversity
}

Banks are institutions that provide various financial services in the collection of savings in the economy, the transfer of funds to the economic units they need, and the development of the money and capital market. anks' money supply is expanding through effective loans supporting growth, while savings are transformed into efficient investments, creating new employment opportunities. In other words, bank loans are an important element for sustainable economic growth. The increase in the banking sector loan volume affects the money supply and increases production and employment. Credit and money are the basis of monetary transfer mechanisms. Monetary policies are classified as expansionary and narrow monetary policies. Monetary policies are used to promote economic development and towards economic growth.

It is seen that there are very different results in terms of countries and periods selected in the literature on the direction of the causality relationship between bank loans, money supply and economic growth. Some studies support that the expansion of bank loans leads to economic growth, while others suggest that economic growth supports bank loan growth, while others suggest that economic growth and the development of bank loans affect each other mutually. In addition, how money supply affects the economic growth variable is a question in the literature. These issues and discussions are important for the effectiveness of monetary policies aimed at ensuring economic growth through bank loans. In this study, the impact of bank loans and money supply on economic growth was investigated. The aim of the study is to determine the effect of money supply indicating the direction of bank loans and monetary policies that represent financial debt to Turkey's economic growth during the period of data retrieval. In addition, it is to look for answers to the questions of 
whether there is an economic growth due to the development of bank loans in Turkey, whether bank loan volume or money supply is increasing as a result of economic growth, and whether there is a two-way causality relationship between economic growth and money supply and bank loans. It is thought that the study will contribute to the literature with the suggestions and recommendations presented in the light of the findings obtained for these questions. Monthly data covering the periods 2005:012020:11 were used in the study. Within the scope of the examination of the relationship between bank loans, money supply and economic growth, industrial production index representing the rate of growth as dependent variable and bank loans variables representing money supply and total loan amounts were selected as independent variables. ARDL boundary test approach for the determination of co-conjunction relationship between variables and Toda-Yamamoto Causality test approach was applied to examine causality relationships. In the study, the importance of loans in terms of economic growth and the effect of money supply on loans and economic growth within the framework of monetary transfer mechanism were evaluated theoretically. According to the results of the ARDL boundary test, when the first two periods between money supply and growth were examined in the short term, it was concluded that increased money supply reduced growth, while a $1 \%$ increase in money supply increased growth by $35 \%$ in the third period. The $1 \%$ increase in bank loans was found to increase growth by $0.86 \%$. In the long term, a $1 \%$ change in money supply reduces growth by $30 \%$, while a $1 \%$ change in bank loans increases growth by $31 \%$. Toda-Yamamoto Granger causality test results show that the causality relationship between bank loans, money supply and growth variables is one-way. The results of the analysis show that bank loans support growth in both the short and long term. It has been determined that banking sector credit growth has a positive effect on growth in Turkey, similar to some studies in the literature. In order for banking sector loans to support economic growth, it is very important that loans are transferred to efficient investment areas other than financing their working capital needs. It is seen that the money supply reduces growth in the first two stages of the short term and positively affects economic growth in the third period. It is seen that bank loans are more effective in economic growth in Turkey than in the supply of money. The 
data obtained reveals that bank loans have been more effective in the growth of the Turkish economy in recent times, while the increase in money supply is not dominant on economic growth. In other words, it is seen that increasing bank loans have accelerated growth within the scope of expansionary monetary policies implemented in Turkey.

\section{Kaynakça / References}

Akı, M.T. (2019). Finansal gelişme ve ekonomik büyüme ilişkisinin nedensellik analizi: Türkiye örneği. Yüksek Lisans Tezi, Trakya Üniversitesi, S.B.E. Edirne.

Arıcan E. ve Okay G. (2014). Ekonomik İstikrarsızlk Ortaminda Merkez Bankalarmmn Uyguladığı Para Politikaları ve Türkiye Örneği. İktisat Politikası Araştırmalan Dergisi,1(1), 1-50.

Dai, F., Liang, L. and Wu, S. (2013) Money supply and economic growth under environmental pressure: the strategy for re-growth, Int. J. Monetary Economics and Finance, 6, (1).55-80.

Aslan Ö. ve Küçükaksoy İ.(2006). Finansal gelişme ve ekonomik büyüme ilişkisi: Türkiye ekonomisi üzerine ekonometrik bir uygulama, İstanbul Üniversitesi İktisat Fakültesi Ekonometri ve İstatistik Dergisi, 4, .12-28.

Baykuş, S. (2020). Finansal gelişme ve ekonomik büyüme arasındaki ilişkinin ampirik analizi: Türkiye örneği. Yüksek Lisans Tezi, Bandırma Onyedi Eylül Üniversitesi, S.B.E. Bandırma.

Beck, T. ve Levine, R. (2004), Stock markets, banks, and growth: panel evidence. Journal of Banking \& Finance, 28,423-442.

BDDK (2021). Bankacillk Sektörü Verileri. https://www.bddk.org.tr/(29.01.2021).

Calderŏn, C. ve Liu, L. (2002), The Direction of Causality Between Financial Development and Economic Growth, Central Bank of Chile, Working Papers No 184.

Ceylan S. ve Durkaya M. (2010), Türkiye'de kredi kullanımı-ekonomik büyüme ilişkisi, Atatürk Üniversitesi İktisadi ve İdari Bilimler Dergisi, 24(2), 21-35.

Çeştepe, H. ve Yıldırım, E. (2016). Türkiye'de finansal gelişme ve ekonomik büyüme ilişkisi. Uluslararası Yönetim İktisat ve İşletme Dergisi, ICAFR 16 Özel Sayısı, 1226.

Demirhan E., Aydemir O. ve İnkaya A.,(2011).The Direction Of Causality between Financial Devolopmentand Economic Growth: Evidence from Turkey, International Journal of Management. 28.(1),3-19.

Holtemöller, O. (2002). Identifying a Credit Channel of Monetary Policy Transmission and Empirical Evidence for Germany. 1-19. 
Idris, M. (2019). Interactive mechanism of money supply and economic growth: Analysis of the causal relationship in Nigeria. International Journal of Academic Research in Business \& Social Sciences. 9(7), 324-338.

İnançlı, S.; N. Altıntaş, V. İnal (2016).Finansal gelişme ve ekonomik büyüme ilişkisi: D-8 Ülkeleri. Kastamonu Üniversitesi Ï̈BF Dergisi, 14,36-49.

İşan, A. (2003). Banka kredilerindeki daralmanm ekonomik etkileri ve krizlerdeki gelişimi. Ankara: TCMB.

QNB Finansbank (2021). Kredi büyüme eğilimi, tüketici kredileri ile hızlandı. https://www.qnbfinansbank.com/medium/document-file-2490.vsf (29.01.2021).

Jalilian, H. ve Kirkpatrick, C. (2002), Financial Development and Poverty Reduction in Developing Countries. In ternational Journal of Finance and Economics, 7, 97108.

Kamacı, A. Ceyhan, M. S., ve Peçe, M.A.(2017). Kredi hacminin para arzı ve ekonomik büyüme üzerine etkisi. Uluslararası Yönetim İktisat ve Isşletme Dergisi, 13(13), 400-409.

Karamelikli, H. ve Keskingöz, H. (2017). Finansal gelişme bileşenlerinin ekonomik büyüme üzerindeki etkisi: Türkiye örneği. İnsan ve Toplum Bilimleri Araştırmaları Dergisi, 6(1), 683-701.

Kar, M. ve Pentecost, J. E. (2000). Financial Development and Economic Growth in Turkey: Further Evidence on the Causality Issue. Loughborough University Department of Economics, Economic Research Paper No 00/27.

Kashyap, A.K. ve Stein, J. C.(1993). Monetary Policy and Bank Lending, NBER Working Paper No. w4317, Available at SSRN: https://ssrn.com/abstract=227020.

King, R. G. ve Levine, R. (1993). Finance and growth, schumperer might be right. Quarterly Journal of Economics, 108(3), 717-737.

Koçak, E. (2014). Türkiye'de çevresel Kuznets eğrisi hipotezinin geçerliliği: ARDL sınır testi yaklaşımı. İşletme ve İktisat Çalşmalan Dergisi, 2(3), 62-73.

Kuttner, K.N. ve Mosser, P.C. (2002). The monetary transmission mechanism: Some answers and further questions. Federal Reserve Bank of New York Economic Policy Review, 15-26.

Levine, R. ve Zervos, S. (1998),Stock markets, banks, and economic growth. American Economic Review, 88, 537-558.

Ndako, U.B. (2010). Financial development, economic growth and stock market volatility: evidence from Nigeria and South Africa. Doctor of Philosophy, University of Leicester, Leicester, England. 
Oktar, S.\&Dalyanc1, L. (2012). Türkiye ekonomisinde para politikasının ekonomik büyüme üzerine etkisi. Marmara Üniversitesi I.I.I.B.F. Dergisi, 32(1), 1-18.

Öztürkler, H. ve Çermikli, A. H. (2007), Türkiye'de bir parasal aktarım kanalı olarak banka kredileri. Finans Politik ve Ekonomik Yorumlar, Dergisi, 44(514),57-68.

Öztürk, İ. (2008). Financial development and economic growth: Evidence from Turkey, Applied Econometrics and International Development, 8(1), 85-98.

Öztürk, S. ve Pehlivan, Ö. S. (2020). Türkiye'de demokrasi ve doğrudan yabancı sermaye yatırımlanı ilişkisi: toda-yamamoto nedensellik analizi (1974-2018). Balkan Journal of Social Sciences/Balkan Sosyal Bilimler Dergisi, 9(17), 113-118.

Pesaran, M. H., Yongcheol, S. ve Richard J. S.. (2001). Bounds testing approaches to the analysis of level relationships, Journal of Applied Econometrics, 16, 289-326.

Rajan, R. G. ve Zingales, L. (1998), Financial Dependence and Growth, The American Economic Review, 88(3),559-586.

Robinson, J. (1952), The generalization of the general theory. In The Rate of Interest and Other Essays, London: Macmillan Press.

Sağlam, Y. ve Sönmez F.E (2017). Finansal gelişme ve ekonomik büyüme arasındaki ilişki: Avrupa geçiş ekonomileri örneği. Eskişehir Osmangazi Üniversitesi İ̈BF Dergisi, 12 (1), 121-140.

Shan, J. ve Morris, A. (2002).Does financial development 'lead' economic growth?, International Review of Applied Economics, 16(2), 18.

Şahin, A. (2011). Türkiye'de banka kredileri ve büyüme ilişkisi üzerine bir uygulama: 1995 2010.Yüksek Lisans Tezi, Dumlupınar Üniversitesi Sosyal Bilimler Enstitüsü.

TCMB (2019). Ylllk Faaliyet Raporu 2019, http://www3.tcmb.gov.tr/yillikrapor/2019/ files/tr-full.pdf(30.01.2021).

TCMB(2021),Kasım Ayı Parasal Glişmeleri, 30 Aralık,2020/ https:// www. tcmb.gov.tr/wps/ wcm/ connect/ fbd95ed0-30d3-4333-9b687d069b83e21/ Parasal+Geli\% C5\%9 Fmeler. pdf?.

Türkmen, E. (2020), Parasal aktarm mekanizmalarndan kredi kanalinn büyümeye etkisi: Bir Uygulama. Doktora Tezi, Marmara Üniversitesi, Bankacillk ve Sigortacllk Enstitüsü.

TÜİK (2021), İstatistikler, https://www.tuik.gov.tr/(29.01.2021).

Turgut, A. ve Ertay, H. İ. (2016), Bankacllk sektörünün ekonomik büyüme üzerindeki etkisi: Türkiye üzerine nedensellik analizi. Aksaray Üniversitesi İktisadi ve İdari Bilimler Fakültesi Dergisi, 8 (4), 114-128. 
Vurur N.S. ve Özen. E. (2013). Türkiye'de mevduat banka kredisi ve ekonomik büyüme ilişkisinin incelenmesi. Uşak Üniversitesi Sosyal Bilimler Dergisi, 6 (3), 117-131.

Yılancı, V. ve Burcu, Ö.. (2010). Yapısal kırılmalar altında Türkiye için savunma harcamaları ile gsmh arasındaki ilişkinin analizi. C.Ü. İktisadi ve İdari Bilimler Dergisi, 11(1): 21-33.

Yllanc1, V. (2015). Zaman serileri analizi sakarya ekonometri semineri. Ders Notları, Sakarya.

\section{Kaynakça Bilgisi / Citation Information}

Yetiz, F. ve Ergin Ünal, A. (2021). Banka kredileri, para arzı ve ekonomik büyüme arasındaki ilişki: Türkiye örneği. OPUS-Uluslararası Toplum Araştırmaları Dergisi, 17(37), 4487-4509. DOI: 10.26466/opus. 873635 